\title{
Artículo Especial: La comunicación de malas noticias
}

\author{
Telling bad news
}

Gabriela Buela*

\begin{abstract}
Al compartir el consultorio con una médica de planta, tuve la oportunidad de conocer a un señor de 70 años que acompañaba a su mujer a la consulta. La señora consultaba porque en el último tiempo había comenzado con episodios de broncoespasmo, por lo que le indicaron "puffs" con salbutamol. La revisamos, la Doctora le enseñó a usar el inhalador y charló un rato sobre el asma y su tratamiento. Antes de terminar la consulta, la señora le pidió amablemente a la Doctora si podía ver unas radiografías de tórax que traía su marido -también su paciente- adelantándole que en el informe decía que había algo anormal. En el lóbulo superior del pulmón derecho, pudimos observar una imagen redondeada, heterogénea, de unos $3 \mathrm{~cm}$ de diámetro y cuyos contornos nos parecieron bastante nítidos, aunque el informe los describía como irregulares. Al ver la imagen, interrogué al paciente sobre tabaquismo y me respondió que fumaba 20 cigarrillos por día; por lo que lo primero que se me ocurrió fue que el paciente podría tener cáncer de pulmón.

La Doctora le explicó que había que estudiar esa imagen más detalladamente y le solicitó una PPD, una tomografía de tórax con contaste y lo cito para cuando tuviera los resultados.
\end{abstract}

Este caso me instaló muchas dudas acerca de como los médicos damos malas noticias a los pacientes y/o a sus familias, una situación frecuente del consultorio, de la sala de internación y hasta de la guardia.

Sin embargo, nadie nos enseña como dar malas noticias. Durante nuestra residencia u otro tipo de entrenamiento formal o informal, la mayoría intentamos copiar las habilidades que vemos utilizar a nuestros "mayores" o modelos de rol. ¿Pero a ellos, quién les ha enseñado? Probablemente hayan hecho lo mismo... Es interesante destacar que durante los cursos de grado no hay materia alguna en la que incluya en su programa como comunicarnos con el paciente, sobre todo en estas circunstancias. En el caso de las enfermedades crónicas con mal pronóstico, como por ejemplo un estadio terminal de un cáncer, muchas veces nos surgen dudas acerca de cómo informar al paciente sobre cuestiones relacionadas a su padecimiento. ¿Deberíamos los médicos de familia u de otra especialidad que implique cuidados longitudinales, adelantarnos a estas situaciones y preguntarle al paciente mientras está sano -o en la primera entrevista- y/o a su familia sus preferencias ante este tipo de circunstancia, que muy probablemente se presentará en un futuro si el tiempo de la relación lo permite? Por otro lado, ¿llegamos a entablar una relación en la que podamos hacer en nuestra cultura este tipo de pregunta a nuestros pacientes?

Lo que veo muy a menudo es que los médicos hablan directamente con la familia, quien finalmente suele decidir según su criterio y sus valores, lo que se supone que será de mayor beneficio para el enfermo. En estas situaciones, que violan el principio de autonomía, el paciente queda sin capacidad para decidir libremente, ya que no se le suministra toda la información. Si bien la familia suele ser el principal soporte emocional del paciente y debe dársele protagonismo, considero que debería funcionar como una aliada para la comunicación con el paciente, sin convertirse en una traba.

Esta introducción me motivó a preguntarme si hay alguna forma de mejorar la comunicación con nuestros pacientes a la hora de darles malas noticias.

Todos estos interrogantes me llevaron a revisar la bibliografía y varios expertos mencionaron como una herramienta útil al protocolo de seis pasos o etapas para dar malas noticias, descripto por Baile y Buckman y que resumimos a continuación:

- Primera etapa: preparar el entorno: el diagnóstico debe estar ya documentado con alto nivel de certeza. Es importante buscar un espacio físico adecuado, donde haya privacidad y tranquilidad, y donde el paciente pueda estar acompañado de sus seres queridos si así lo desea. Es conveniente dar la información personalmente, ya que permite acompañar la respuesta emocional del paciente.
- Segunda etapa: averiguar qué sabe el paciente sobre la enfermedad: es importante utilizar preguntas abiertas como: ¿qué le dijeron sobre su enfermedad?, ¿está preocupado?

- Tercera etapa: reconocer lo que el paciente quiere saber: averiguamos que quiere saber de su enfermedad a través de preguntas como: ¿quiere que le cuente algo sobre su enfermedad? Durante esta etapa es importante respetar los silencios, las evasivas o las negativas a ser informado, pero se debe ofrecer una nueva posibilidad de charlar sobre el tema, invitándolo a conversar cuando el lo desee o lo necesite.

- Cuarta etapa: compartir la información: si en la anterior etapa el paciente solicita ser informado se recomienda que la información se vaya dando en forma gradual, dando tiempo a que el enfermo vaya asimilando la gravedad de su dolencia, y respetando su ritmo, su deseo y/o su capacidad para ser informado; así como aceptando sus ilusiones y sus esperanzas. En cada entrevista, es bueno hacer un resumen comprobando qué entendió el paciente, enfatizando las posibilidades terapéuticas y/o curativas si las hay.

- Quinta etapa: responder a los sentimientos del paciente: las reacciones más frecuentes son la ansiedad, el miedo, la tristeza, la agresividad, la negación y la ambivalencia afectiva. Todas las respuestas pueden mezclarse y hay que respetarlas, estando atentos a las mismas para poder ayudar al paciente y a su familia. Es en esta etapa cuando puede aparecer la soledad más profunda, sobre todo si la información no ha sido clara y compartida por el entorno.

- Sexta etapa: plan de cuidados: esta etapa comprende la oferta de un plan de cuidados para apoyarlo, aliviarle los síntomas y compartir sus preocupaciones y miedos del paciente. En general conviene aumentar la frecuencia de entrevistas, realizar visitas domiciliarias y asegurar el acceso a la comunicación con el equipo de salud. Es importante pesquisar si el paciente presenta depresión, dolor o insomnio, con el objetivo de ayudarlo a mejorar su confort, y a los signos de agotamiento en los cuidadores, con el fin de ayudarlos a instrumentar medidas que los alivien.

\section{Conclusión}

Las etapas de Baile y Buckman previamente descriptas pueden ayudarnos a ordenar nuestra conducta ante este tipo de situaciones. Considero que quienes seguimos pacientes y familiar de una forma longitudinal, ocupamos un rol fundamental a la hora de dar malas noticias, siendo importante que nos entrenemos para ello y que contemos con espacios de supervisión para contribuir a que la calidad de nuestro trabajo y de nuestra salud sea lo mejor posible.

Recibido el 10/06/08 y aceptado el 25/08/08.

Referencias

1. Baile W, Buckman R y col. SPIKES-A six-step protocol for delivering bad news: Applications to the patients with cancer. The Oncologist. 2000; 5:302-11. Citado por: García Díaz F. Comunicando malas noticias en Medicina: recomendaciones para hacer de la necesidad virtud. Medicina Intensiva. Vol 30 (09): $452-459$. Disponible en URL: http://db.doyma.es/cgi-bin/wdbcgi.exe/doyma/mrevista.fulltext?pident=13096531 (último acceso 25/08/08)

2. Alves de Lima A. ¿Cómo comunicar malas noticias a nuestros pacientes y no morir en el intento? Revista Argentina de Cardiología. Vol. 71 № 3 / Mayo-Junio 2003 . Disponible en URL: http://www.umng.edu.co/www/resources/cmnoticias.pdf (último acceso 25/08/08).

* Residente de primer año del Servicio de Medicina Familiar y Comunitaria del Hospital Italiano de Buenos Aires. gabriela.buela@hospitalitaliano.org.ar 